\title{
Fugong virus, a novel hantavirus harbored by the small oriental vole (Eothenomys eleusis) in China
}

\author{
Xing-Yi Ge', Wei-Hong Yang ${ }^{2}$, Hong Pan², Ji-Hua Zhou², Xi Han², Guang-Jian Zhu' ${ }^{3}$, James S. Desmond ${ }^{3}$, \\ Peter Daszak ${ }^{3}$, Zheng-Li Shi ${ }^{1}$ and Yun-Zhi Zhang ${ }^{2^{*}}$
}

\begin{abstract}
Background: Rodents are natural reservoirs of hantaviruses, which cause two disease types: hemorrhagic fever with renal syndrome in Eurasia and hantavirus pulmonary syndrome in North America. Hantaviruses related human cases have been observed throughout Asia, Europe, Africa, and North America. To date, 23 distinct species of hantaviruses, hosted by reservoir, have been identified. However, the diversity and number of hantaviruses are likely underestimated in China, and hantavirus species that cause disease in many regions, including Yunnan province, are unknown.

Results: In August 2012, we collected tissue samples from 189 captured animals, including 15 species belonging to 10 genera, 5 families, and 4 orders in Fugong county, Yunnan province, China. Seven species were positive for hantavirus: Eothenomys eleusis (42/94), Apodemus peninsulae (3/25), Niviventer eha (3/27), Cryptotis montivaga (2/8), Anourosorex squamipes (1/1), Sorex araneus (1/1), and Mustela sibirica (1/2). We characterized one full-length genomic sequence of the virus (named fugong virus, FUGV) from a small oriental vole (Eothenomys eleusis). The full-length sequences of the small, medium, and large segments of FUGV were 1813, 3630, and $6531 \mathrm{nt}$, respectively. FUGV was most closely related to hantavirus LX309, a previously reported species detected in the red-backed vole in Luxi county, Yunnan province, China. However, the amino acid sequences of nucleocapsid (N), glycoprotein $(\mathrm{G})$, and large protein $(\mathrm{L})$ were highly divergent from those of Hantavirus LX309, with amino acid differences of 11.2, 15.3, and 12.7 \%, respectively. In phylogenetic trees, FUGV clustered in the lineage corresponding to hantaviruses carried by rodents in the subfamily Arvicolinae.
\end{abstract}

Conclusions: High prevalence of hantavirus infection in small mammals was found in Fugong county, Yunnan province, China. A novel hantavirus species FUGV was identified from the small oriental vole. This virus is phylogenetic clustering with another hantavirus LX309, but shows highly genomic divergence.

Keywords: Eothenomys eleusis, Hantavirus, Hemorrhagic fever with renal syndrome, Genome, Vole

\section{Background}

Hantaviruses (genus Hantavirus, family Bunyaviridae) cause two disease types: hemorrhagic fever with renal syndrome (HFRS) in Eurasia and hantavirus pulmonary syndrome (HPS) in North America [1]. The hantavirus genome is composed of three segments, designated the large (L), medium (M), and small (S) segments, which encode an RNA-dependent RNA polymerase [2, 3], a

\footnotetext{
* Correspondence: zhangyunzhi1818@163.com

${ }^{2}$ Yunnan Provincial Key Laboratory for Zoonosis Control and Prevention, Yunnan Institute of Endemic Diseases Control and Prevention, Dali 671000, China

Full list of author information is available at the end of the article
}

glycoprotein precursor that is cotranslationally processed to produce two envelope glycoproteins ( $\mathrm{Gn}$ and $\mathrm{Gc}$ ), and a nucleocapsid $(\mathrm{N})$ protein, respectively $[3,4]$. HFRS is a typical rodent-borne disease and a severe public health issue in China [5]. In addition to rodents, hantaviruses have recently been detected in shrews (order Soricomorpha, family Soricidae and Talpidae) [6-11] and bats (order Chiroptera, family Rhinolophidae, Hipposideridae, Vespertilionidae, and Nycteridae) [12-16], but it is not clear whether these hantaviruses lead to human illness. It is believed that only hantaviruses in rodent hosts (order Rodentia, family or subfamily Muridae, Arvicolinae, and 
Sigmodontinae) cause HFRS and HPS in Asia, Europe, Africa, and North America [17]. To date, 23 distinct hantavirus species are recognized by the ICTV [18]. In China, two main hantaviruses, Hantaan virus (HTNV) carried by the striped field mouse (Apodemus agrarius) and Seoul virus (SEOV) carried by the Norway rat (Rattus norvegicus), cause HFRS [19]. In 2012, we reported a novel hantavirus harbored by the Yunnan red-backed vole (Eothenomys miletus) [20]. In this study, we identified another novel hantavirus in the small oriental vole (Eothenomys eleusis, subfamily Arvicolinae), designated Fugong virus (FUGV) because it was recovered in Fugong county, Yunnan Province, China. The small oriental vole is distributed widely in Hunan, Hubei, Sichuan, Yunnan, and Guizhou, China [21].

\section{Methods}

\section{Animal sampling}

In August 2012, 189 small mammals were captured in forests of the suburbs of Fugong county, Yunnan province. Animal species were identified based on morphology, and animal weight and sex were recorded. Species were further identified by DNA sequencing of the mitochondrial cytochrome b $(C y t B)$ gene following previously described methods [22]. Animal lung tissues were collected for further analysis.

\section{Direct immunofluorescence assay (IFA) detection of hantavirus}

Hantavirus antigens present in the lung tissue samples were detected by direct immunofluorescence assay (IFA) as previously described [23]. Briefly, animal lung tissue samples were fixed and cut into $4-\mu \mathrm{m}$ sections using a Cryocut microtome (KD-1508 Frigocut; Zhejiang, China) at $-25{ }^{\circ} \mathrm{C}$ and fixed in cold acetone. Sections were stained with rabbit anti-SEOV/Z37 or $\mathrm{HTNV} / \mathrm{Z10}$ antibodies labeled with fluorescein isothiocyanate (FITC) (Zhejiang CDC) [24]. Scattered, granular fluorescence in the cytoplasm was considered positive staining.

\section{DNA and RNA extraction and reverse transcription PCR}

Total DNA was extracted using the DNeasy Blood \& Tissue Kit (Qiagen, Hilden, Germany) from tissue samples according to the manufacturer's protocol. Viral RNA was extracted from lung tissues using the QIAamp Viral RNA Mini Kit (Qiagen) following the manufacturer's instructions, and cDNA was synthesized with M-MLV reverse transcriptase (Promega, Madison, WI, USA) in the presence of the primer P14 [25].

Tissues from positive samples were screened by reverse transcription PCR (RT-PCR) using degenerate primers based on the conserved domain of the $\mathrm{L}$ fragment of Hantavirus genomes [26]. Standard precautions were taken to avoid PCR contamination, and no false-positives were observed in negative controls. PCR products were gel purified and sequenced with both forward and reverse primers using the 3100 Sequencer (ABI, Waltham, MA, USA).

\section{Genomic sequencing}

One positive sample of E. eleusis was chosen for hantavirus genomic sequencing. The complete genomic sequence was amplified by PCR using primers designed from published hantavirus sequences or from sequences obtained in this study (available upon request). PCR products were also gel purified and sequenced with both forward and reverse primers using the 3100 Sequencer (ABI). The sequencing chromatograms were inspected carefully for overlapping multicolor peaks, which are an indicator of sequence heterogeneity in the amplicons. The PCR products of these samples were cloned into the pGEM-T Easy Vector (Promega) and at least 5 clones for each PCR fragment were sequenced to obtain a consensus sequence.

\section{Sequence analysis}

Preliminary sequence management and analysis were carried out using Geneious (Version 5.5.9, Biomatters Limited, Aukland, New Zealand) and sequence alignment and editing were performed using ClustalW (Version 2.0) [27] and BioEdit (Version 7.1.9) [28]. The potential in vitro recombinant sequences (i.e., PCR artifacts) were screened and discarded using Recombination Detection Program v2.0 [29]. The consensus sequences were compared with known hantavirus sequences available in GenBank. Phylogenetic trees were constructed using the maximum likelihood (ML) algorithm with bootstrap values determined by 1000 replicates in Geneious.

\section{Results}

\section{Detection of hantaviruses in several animals}

The sampled animals consisted of 15 species belonging to 10 genera, 5 families, and 4 orders. A total of $49.74 \%$ of captured animals (94/189) were E. eleusis, indicating that it may be the dominant species in the sampling area in Fugong ( $C y t B$ GenBank No: KT899700). A summary of the species observed in the study is provided in Table 1. Based on IFA for all lung tissue samples (Fig. 1), hantaviruses were detected in 7 species: Eothenomys eleusis (42/ 94), Apodemus peninsulae (3/25), Niviventer eha (3/27), Cryptotis montivaga (2/8), Anourosorex squamipes (1/1), Sorex Araneus (1/1), and Mustela sibirica (1/2) (Table 1).

Hantavirus RNA was detected in 21 of 42 IFA-positive samples of E. eleusis. PCR amplification of the hantavirus sequence from samples obtained from 6 additional species failed. We sequenced all of the amplified fragments and found that the 420-nt (nucleotide) sequences were highly similar, with $>99 \%$ nt sequence identities. The hantavirus was named Fugong virus (FUGV). 
Table 1 Detection of hantavirus in small mammals in Fugong County, Yunnan Province, China in 2012

\begin{tabular}{|c|c|c|}
\hline \multirow[t]{2}{*}{ Animal species } & \multicolumn{2}{|c|}{ Virus Counts (Positive/Tested) } \\
\hline & IFA & Nested RT-PCR \\
\hline \multicolumn{3}{|c|}{ Rodentia, Cricetidae, Eothenomys } \\
\hline Eothenomys eleusis & $42 / 94$ & $21 / 94$ \\
\hline \multicolumn{3}{|c|}{ Rodentia, Muridae, Apodemus } \\
\hline Apodemus peninsulae & $3 / 25$ & $0 / 25$ \\
\hline Apodemus latronum & 0/9 & $0 / 9$ \\
\hline Apodemus chevrieri & $0 / 4$ & $0 / 4$ \\
\hline Apodemus draco & $0 / 1$ & $0 / 1$ \\
\hline \multicolumn{3}{|c|}{ Rodentia, Muridae, Niviventer } \\
\hline Niviventer eha & $3 / 27$ & $0 / 27$ \\
\hline Niviventer coxingi & $0 / 2$ & $0 / 2$ \\
\hline \multicolumn{3}{|l|}{ Rodentia, Muridae, Vernaya } \\
\hline Vernaya fulva & $0 / 1$ & $0 / 1$ \\
\hline \multicolumn{3}{|c|}{ Soricomorpha, Soricidae, Crocidura } \\
\hline Crocidura attenuata & $0 / 7$ & $0 / 7$ \\
\hline \multicolumn{3}{|c|}{ Soricomorpha, Soricidae, Cryptotis } \\
\hline Cryptotis montivaga & $2 / 8$ & $0 / 8$ \\
\hline \multicolumn{3}{|c|}{ Soricomorpha, Soricidae, Anourosorex } \\
\hline Anourosorex squamipes & $1 / 1$ & $0 / 1$ \\
\hline \multicolumn{3}{|c|}{ Soricomorpha, Soricidae, Sorex } \\
\hline Sorex Araneus & $1 / 1$ & $0 / 1$ \\
\hline Sorex alpinus & $0 / 4$ & $0 / 4$ \\
\hline \multicolumn{3}{|c|}{ Lagomorpha, Ochotomidae, Ochotona } \\
\hline Ochotona thibetana & $0 / 3$ & $0 / 3$ \\
\hline \multicolumn{3}{|c|}{ Carnivora, Mustelidae, Mustela } \\
\hline Mustela sibirica & $1 / 2$ & $0 / 2$ \\
\hline Total & $53 / 189$ & $21 / 189$ \\
\hline
\end{tabular}

\section{Genetic characterization and analysis}

The full-length genomic sequence of FUGV from one positive sample obtained from E. eleusis (No.10) was determined (GenBank No: KT899701, KT899702, and KT899703). The full-length S-genomic segment was
$1813 \mathrm{nt}$ and encoded a predicted $\mathrm{N}$ protein of 435 aa; it contained noncoding regions (NCR) of 43 and $463 \mathrm{nt}$ at the $5^{\prime}$ - and 3 '-regions, respectively (Table 2). The entire M-genomic segment was $3630 \mathrm{nt}$ and encoded a predicted glycoprotein of 1190 aa; it contained NCRs of 58 and 152 nt at the 5'- and 3'-regions, respectively. For most hantaviruses, a conserved pentapeptide, WAASA, located at the end of $\mathrm{Gn}$ is presumed to be the proteolytic cleavage site to process the glycoprotein precursor into Gn and Gc [30]. Here, a variant WAVSA pentapeptide motif located at aa 648-652 was found. Moreover, using the NetNGlyc 1.0 server, six potential N-linked glycosylation sites in Gn and Gc at positions 136, 351, 403, 566, 579, and 931 were found.

The full-length L-genomic segment was $6531 \mathrm{nt}$ and encoded an RNA-dependent RNA polymerase of 2152 aa; it contained NCRs of 37 and 35 nt at the 5'- and 3'ends, respectively. Previous studies have identified five conserved motifs (A, B, C, D, and E) in hantavirus RNA polymerases [31, 32]. These motifs were all detected in the FUGV L protein. In addition, other typical conserved motifs among hantavirus RNA polymerases, like premotif $\mathrm{A}$ and the acidic C-terminal domain [31], were found (data not shown).

A pairwise alignment and comparison with known hantavirus genomes (from previously detected species or strains) showed low nt sequence similarity in the $\mathrm{S}, \mathrm{M}$, and $\mathrm{L}$ segments, ranging from 41.5 to $63.1 \%, 51.1$ to $75.5 \%$, and 61.9 to $76.3 \%$, respectively (Table 2). Deduced aa similarities were higher (45.6-88.8\%, 41.5-84.7\%, and 61.5-87.3\% for the $\mathrm{N}, \mathrm{Gn} / \mathrm{Gc}$, and L proteins, respectively). Additionally, all of the FUGV segments were most closely related to Hantavirus LX309 sequences, which is a putative novel hantavirus species found in the red-backed vole in Luxi County, Yunnan, China [20]. However, the aa sequences were highly divergent between the N, G, and L proteins of FUGV and Hantavirus LX309, with differences reaching 11.2, 15.3, and $12.7 \%$, respectively.
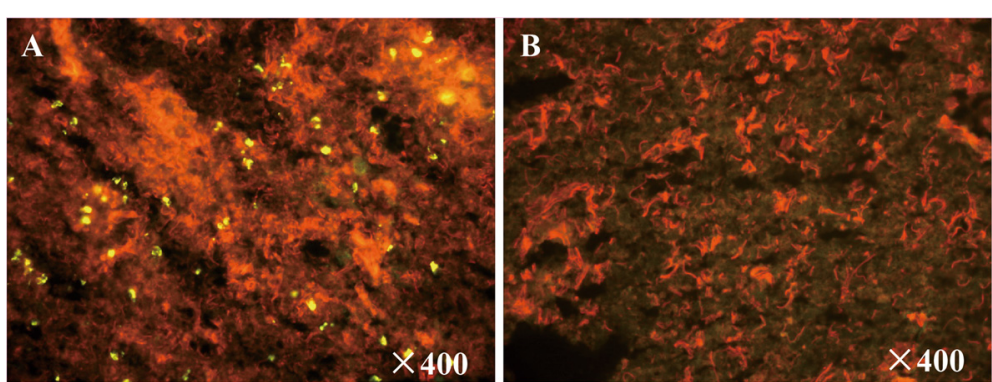

Fig. 1 Detection of hantavirus in lung samples of Eothenomys eleusis by immunofluorescence. a: positive; b: negative. Yellow granular dots represent positive staining 
Table 2 Nucleotide and amino acid sequence similarity (\%) between FUGV virus and representative hantaviruses (23 ICTV-nominated species and two closely related viruses LX309 and YN06-862)

\begin{tabular}{|c|c|c|c|c|c|c|}
\hline \multirow[b]{3}{*}{ Virus species (strain) } & \multicolumn{6}{|c|}{ nt and aa identities (\%) } \\
\hline & \multicolumn{2}{|c|}{ S segment } & \multicolumn{2}{|c|}{ M segment } & \multicolumn{2}{|c|}{$\underline{L}$ segment } \\
\hline & $1813 \mathrm{nt}$ & 435 aа & $3636 \mathrm{nt}$ & 1139 aа & $6531 \mathrm{nt}$ & 2152 aа \\
\hline Hantavirus LX309 & 63.1 & 88.8 & 75.7 & 84.7 & 76.3 & 87.3 \\
\hline Hantavirus YN06-862 & 91.1 & 99 & - & - & - & - \\
\hline Andes virus Chile-9717869 & 51.9 & 77.9 & 63.1 & 65.6 & 71.6 & 78 \\
\hline Bayou virus F0260003 & 53.4 & 78.3 & 62.2 & 64.5 & 70.8 & 77.7 \\
\hline Black Creek Canal virus & 54 & 72.3 & 62.7 & 65.4 & 71.2 & 77.4 \\
\hline Cano Delgadito virus VHV-574 & 53.5 & 72.8 & 61.3 & 62.9 & 71.4 & 78.1 \\
\hline Dobrava-Belgrade virus Afl9/1999 & 45.3 & 60.9 & 56.9 & 54.6 & 66 & 68.8 \\
\hline El Moro Canyon virus RM-97 & 52.2 & 75.6 & 60.0 & 66.3 & - & - \\
\hline Hantaan virus $76-118$ & 43.7 & 62.7 & 57.2 & 55.2 & 66.3 & 67.9 \\
\hline Isla Vista virus MC-SB-1 & 51.7 & 79 & - & - & - & - \\
\hline Khabarovsk virus Fuyuan-Mm-312 & 51.6 & 75.1 & 66.5 & 71 & 72.6 & 79.5 \\
\hline Laguna Negra virus 510B & 52.6 & 75.8 & 62.5 & 64.9 & - & - \\
\hline Muleshoe virus SH-Tx-339 & 54.4 & 77.4 & - & - & - & - \\
\hline New York virus NY-2 & 53 & 74.9 & 62.9 & 65.6 & - & - \\
\hline Prospect Hill virus $\mathrm{PH}-1$ & 50.9 & 77.4 & 67.5 & 71.5 & 70.6 & 79.5 \\
\hline Puumala virus Sotkamo & 50.8 & 74 & 66.5 & 69.8 & 72.2 & 79.3 \\
\hline Rio Mamore virus HTN-007 & 52.6 & 77 & 63.2 & 65.6 & 70.9 & 78.3 \\
\hline Rio Segundo virus RMx-Costa-1 & 51.9 & 75.1 & - & - & - & - \\
\hline Saaremaa virus Saaremaa-160v & 44.7 & 60.4 & - & - & 66.1 & 69.1 \\
\hline Sangassou virus SA14 & 44.8 & 61.6 & 56.6 & 53.8 & 66.6 & 67.8 \\
\hline Seoul virus 80-39 & 44.8 & 62.7 & 56.3 & 53.6 & 66.3 & 67.8 \\
\hline Sin Nombre virus NM H10 & 52.3 & 75.1 & 63.1 & 65.9 & 71.6 & 77.8 \\
\hline Thailand virus Anjozorobe & 45.9 & 61.6 & 55.3 & 53.5 & 66 & 68.3 \\
\hline Thottapalayam virus VRC 66412 & 41.5 & 45.3 & 51.1 & 41.5 & 61.9 & 61.5 \\
\hline Topografov virus Ls136V & 53.4 & 74.4 & 65 & 71.3 & - & - \\
\hline Tula virus Moravia/5302v/95 & 51.3 & 77 & 67.5 & 71.5 & 72.5 & 80 \\
\hline
\end{tabular}

IFA, immunofluorescence analysis; RT-PCR, reverse transcription PCR

\section{Phylogenetic analyses}

To determine the phylogenetic relationships among FUGV isolated in this study and previously described hantaviruses, the genomic segments of FUGV were aligned with those of representative hantavirus species (or strains) available in GenBank. Both nt and aa ML phylogenetic trees (based on coding regions and the predicted deduced protein sequences of the $S, M$, and L segments, respectively) were estimated. Either one or two genomic segments for several viruses were unavailable (e.g., the $E l$ Moro Canyon virus genome lacked the $\mathrm{L}$ region and the Isla Vista virus lacked $\mathrm{M}$ and $\mathrm{L}$ sequences); accordingly, the phylogenetic trees based on each genomic segment consisted of different numbers or combinations of viral taxa. Despite this, the nt and aa trees presented a consistent branching pattern and topology (Fig. 2). In the S, M, and L trees, FUGV clustered in the phylogenetic lineage that corresponded to viruses harbored by rodents in the subfamily Arvicolinae. In the $\mathrm{M}$ and $\mathrm{L}$ trees, FUGV and LX309 formed a distinct clade, both of which have been detected in the genus Eothenomys (Arvicolinae: Cricetidae) [20]. We noticed that another hantavirus in the database, YN06-862 (for which only the S segment was available in the database, and which lacked an associated publication, GenBank No. AEF12618), was most closely related to FUGV. YN06-862 was also detected in E. eleusis in Yunnan, China.

To infer the evolutionary relationships for FUGV and its host, an ML tree was built using mitochondrial $C y t B$ of the Rodentia hosts of representative hantaviruses, and Soricomorpha hosts were used as an outgroup (Fig. 2c). The tree of the hosts was in agreement with that of 

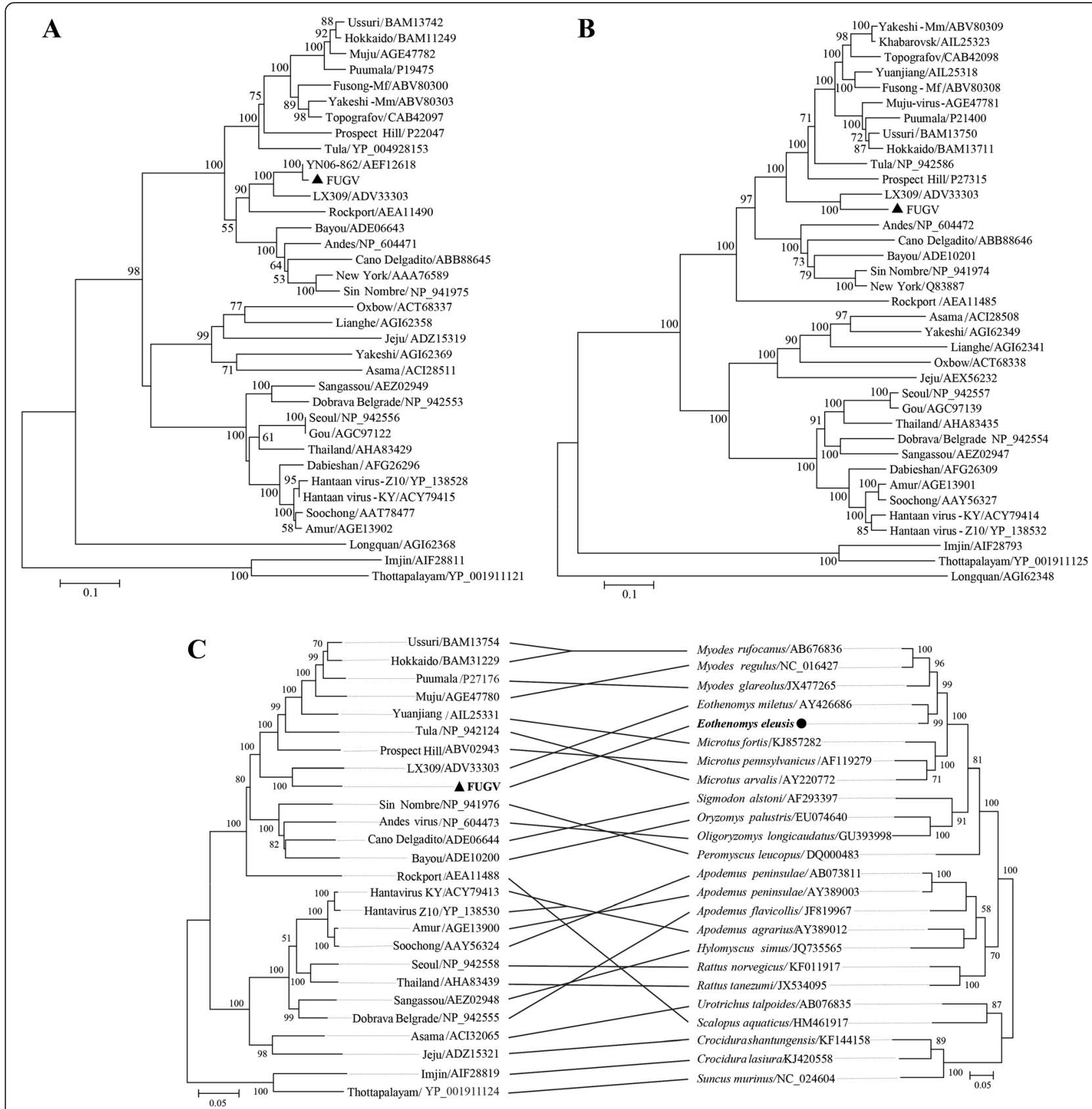

Fig. 2 Phylogenetic analysis of hantaviruses and their hosts based on the $L \mathbf{a}, M \mathbf{b}$, and $S$ segments and CytB $\mathbf{c}$. Coding regions of the FUGV genome were aligned with sequences of representative hantavirus species (or strains) in GenBank, the alignments were used to generate ML trees, and the same method was used to build a Cytb tree. Bootstrap values greater than $50 \%$ are shown at the branches. The GenBank accession numbers and the names of corresponding viruses are shown. FUGV and its Eothenomys eleusis host are labeled with triangles and circles, respectively

previous studies; the Murinae subfamily and Cricetidae family formed two monophyletic groups, with Soricomorpha as the outgroup. The Cricetidae were further subdivided into the subfamilies Arvicolinae, Neotominae, and Sigmodontinae [14]. To understand virus-host co-divergence, the $\mathrm{L}$ tree of viruses were compared with the $C y t B$ tree of hosts. We found that FUGV and
LX309 diverged earlier than Prospect Hill virus, Tula virus, Puumala virus, and others, which was not congruent with their Myodes spp. host evolutionary statuses in the $C y t B$ tree. This phenomenon may be explained by differences in the evolutionary rates of hantaviruses in different hosts. In the tree, the same phenomenon can also can be observed for Sangassou 
virus and Hylomyscus simus (African wood mouse), and for Dobrava-Belgrade virus and Apodemus flavicollis (yellow-necked mouse) [33, 34].

\section{Discussion}

Hantavirus antigens were detected by direct IFA in 7 out of 15 total species collected in Fugong county, Yunnan Province. We successfully amplified the nucleotide sequences of the virus obtained from E. eleusis. These results suggested a high cross-reactivity of SEOV and HTNV with other hantaviruses in serological level, but their genomic sequences were highly divergent. We thus suspected that there were other novel hantaviruses that cannot be detected with the degenerate primers used in this study. We also cannot exclude potential RT-PCR sensitivity issues.

The three segments of FUGV harbored by E. eleusis were most closely related to Hantavirus LX309 carried by E. miletus. However, the aa sequences of the $\mathrm{N}, \mathrm{G}$, and $\mathrm{L}$ proteins of FUGV were highly divergent with respect to Hantavirus LX309, with similarities reaching 11.2, 15.3, and $12.7 \%$, respectively. The new ICTV classification guidelines indicate that a novel Hantavirus species should show at least a $10 \%$ difference in S segment similarity and a $12 \%$ difference in $\mathrm{M}$ segment similarity based on complete amino acid sequences [35]. Accordingly, the hantavirus harbored by E. eleusis represents a novel species. Additionally, no reassortment or recombination events were detected among FUGV and other hantaviruses. We propose that this novel species be named Fugong virus (FUGV) based on the location where it was first recovered.

In phylogenetic analyses of the three segments of the FUGV genome, it grouped with hantaviruses harbored by rodents in the subfamily Arvicolinae, which can cause HFRS in Eurasia. For example, the Puumala virus (PUUV) harbored by Arvicolinae (Myodes glareolus) causes most HFRS cases, with 35,424 reported cases in 2006 [36, 37]. Recently, more than 100 HFRS cases have been reported in Yunnan province (unpublished data). However, the types of hantaviruses that cause HFRS in Yunnan province are still unknown. It is not clear whether FUGV can infect humans and lead to illness.

Phylogenetic analyses of hantaviruses and their rodent hosts suggested that the viruses have a long history of coevolution with their predominant rodent carriers $[38,39]$. FUGV was most closely related to hantavirus LX309, which is carried by different rodent species within the same genus. Additionally, we detected differences in the evolutionary rates of hantaviruses in different hosts. The Eothenomys genus consists of eight rodent species, but only two have been investigated. Considering the high prevalence and diversity of hantaviruses in the genus, additional investigations should be performed in the future to extend the number of species considered.

Competing interests

The authors declare that they have no competing interests.

\section{Authors' contributions}

YZZ, WHY, JHZ, GJZ, and JSD collected samples. HP, XH, and JHZ carried out the immunoassays. XYG performed molecular studies and phyolgenetic analysis. ZLS and PD participated in the design of the study and helped to draft the manuscript. YZZ and XYG conceived of the study and drafted the manuscript. All authors read and approved the final manuscript.

\section{Acknowledgements}

This work was jointly funded by the National Natural Science Foundation of China $(81260437 ; 81060132 ; 81290341)$, the Project of State Key Laboratory for Infectious Diseases Prevention and Control (2013SKLID302), the Scientific and Technological Basis Special Project from the Minister of Science and Technology of the People's Republic of China (2013FY113500), and the China Mega-Project for Infectious Disease (2014ZX10004001-003) from the Minister of Science and Technology of the People's Republic of China.

\section{Declarations}

This study was reviewed and approved by the Ethics Committee of the Yunnan Institute of Endemic Disease Control and Prevention. All animals were treated in strict according to the guidelines for the Laboratory Animal Use and Care from the Chinese CDC and the Rules for the Implementation of Laboratory Animal Medicine (1998) from the Ministry of Health, China, under the protocols approved by the National Institute for Communicable Disease Control and Prevention. All surgery was performed under ether anesthesia, and all efforts were made to minimize suffering.

\section{Author details}

${ }^{1}$ Key Laboratory of Special Pathogens, Wuhan Institute of Virology, Chinese Academy of Sciences, Wuhan 430071, China. ${ }^{2}$ Yunnan Provincial Key Laboratory for Zoonosis Control and Prevention, Yunnan Institute of Endemic Diseases Control and Prevention, Dali 671000, China. ${ }^{3}$ EcoHealth Alliance, New York, NY 10001, USA.

Received: 16 December 2015 Accepted: 2 February 2016

Published online: 16 February 2016

References

1. Schmaljohn C, Hjelle B. Hantaviruses: a global disease problem. Emerg Infect Dis. 1997:3:95-104

2. Kukkonen SK, Vaheri A, Plyusnin A. Completion of the Tula hantavirus genome sequence: properties of the $L$ segment and heterogeneity found in the 3' termini of S and L genome RNAs. J Gen Virol. 1998;79:2615-22.

3. Schmaljohn CS, Hasty SE, Harrison SA, Dalrymple JM. Characterization of Hantaan virions, the prototype virus of hemorrhagic fever with renal syndrome. J Infect Dis. 1983;148:1005-12.

4. Plyusnin A, Vapalahti O, Vaheri A. Hantaviruses: genome structure, expression and evolution. J Gen Virol. 1996;77:2677-87.

5. Huang $X$, Yin $H$, Yan L, Wang X, Wang S. Epidemiologic characteristics of haemorrhagic fever with renal syndrome in Mainland China from 2006 to 2010. Western Pac Surveill Response J. 2012:3:12-8.

6. Arai S, Ohdachi SD, Asakawa M, Kang HJ, Mocz G, et al. Molecular phylogeny of a newfound hantavirus in the Japanese shrew mole (Urotrichus talpoides). Proc Natl Acad Sci U S A. 2008;105:16296-301.

7. Gu SH, Kang HJ, Baek LJ, Noh JY, Kim HC, et al. Genetic diversity of Imjin virus in the Ussuri white-toothed shrew (Crocidura lasiura) in the Republic of Korea, 2004-2010. Virol J. 2011:8:56.

8. Klempa B, Fichet-Calvet E, Lecompte E, Auste B, Aniskin V, et al. Novel hantavirus sequences in Shrew, Guinea. Emerg Infect Dis. 2007;13:520-2.

9. Radosa L, Schlegel M, Gebauer P, Ansorge H, Heroldova M, et al. Detection of shrew-borne hantavirus in Eurasian pygmy shrew (Sorex minutus) in Central Europe. Infect Genet Evol. 2013;19:403-10.

10. Song JW, Kang HJ, Gu SH, Moon SS, Bennett SN, et al. Characterization of Imjin virus, a newly isolated hantavirus from the Ussuri white-toothed shrew (Crocidura lasiura). J Virol. 2009;83:6184-91. 
11. Zuo SQ, Gong ZD, Fang LQ, Jiang JF, Zhang JS, et al. A new hantavirus from the stripe-backed shrew (Sorex cylindricauda) in the People's Republic of China. Virus Res. 2014;184:82-6.

12. Weiss S, Witkowski PT, Auste B, Nowak K, Weber N, et al. Hantavirus in bat, Sierra Leone. Emerg Infect Dis. 2012;18:159-61.

13. Sumibcay L, Kadjo B, Gu SH, Kang HJ, Lim BK, et al. Divergent lineage of a novel hantavirus in the banana pipistrelle (Neoromicia nanus) in Cote d'lvoire. Virol J. 2012;9:34.

14. Guo WP, Lin XD, Wang W, Tian JH, Cong ML, et al. Phylogeny and origins of hantaviruses harbored by bats, insectivores, and rodents. PLoS Pathog. 2013; 9:e1003159.

15. Gu SH, Lim BK, Kadjo B, Arai S, Kim JA, et al. Molecular phylogeny of hantaviruses harbored by insectivorous bats in Cote d'Ivoire and Vietnam. Viruses. 2014;6:1897-910.

16. Xu L, Wu J, He B, Qin S, Xia L, et al. Novel hantavirus identified in black-bearded tomb bats, China. Infect Genet Evol. 2015;31:158-60.

17. Jonsson CB, Fiqueiredo LT, Vapalahti O. A global perspective on hantavirus ecology, epidemiology, and disease. Clin Microbiol Rev. 2010;23:412-41.

18. Plyusnin A, Beatty BJ, Elliott RM, Goldbach R, Kormelink R, et al. In: King $A M Q$, Lefkowitz EJ, Adams MJ, Carstens EB, editors. Ninth report of the International Committee on Taxonomy of Viruses. Bunyaviridae. San Diego, CA, USA: Elsevier Academic Press; 2012. p. 725-41.

19. Zhang $Y$, Zhang $H$, Dong $X$, Yuan J, Zhang $H$, et al. Hantavirus outbreak associated with laboratory rats in Yunnan, China. Infect Genet Evol. 2010;10:638-44.

20. Zhang Y, Yuan J, Yang X, Zhou J, Yang W, et al. A novel hantavirus detected in Yunnan red-backed vole (Eothenomys miletus) in China. J Gen Virol. 2011;92:1454-7.

21. Luo J, Yang D, Suzuki H, Wang Y, Chen WJ, et al. Molecular phylogeny and biogeography of Oriental voles: genus Eothenomys (Muridae, Mammalia). Mol Phylogenet Evol. 2004;33:349-62.

22. Ge XY, Li JL, Yang XL, Chmura AA, Zhu G, et al. Isolation and characterization of a bat SARS-like coronavirus that uses the ACE2 receptor. Nature. 2013:503:535-8.

23. Wang $H$, Yoshimatsu K, Ebihara H, Ogino M, Araki K, et al. Genetic diversity of hantaviruses isolated in china and characterization of novel hantaviruses isolated from Niviventer confucianus and Rattus rattus. Virology. 2000;278:332-45.

24. Jiang JF, Zuo SQ, Zhang WY, Wu XM, Tang F, et al. Prevalence and genetic diversities of hantaviruses in rodents in Beijing, China. Am J Trop Med Hyg. 2008;78:98-105.

25. Schmaljohn CS, Jennings GB, Hay J, Dalrymple JM. Coding strategy of the S genome segment of Hantaan virus. Virology. 1986;155:633-43.

26. Klempa B, Fichet-Calvet E, Lecompte E, Auste B, Aniskin V, et al. Hantavirus in African wood mouse, Guinea. Emerg Infect Dis. 2006:12:838-40.

27. Larkin MA, Blackshields G, Brown NP, Chenna R, McGettigan PA, et al. Clustal $W$ and Clustal $X$ version 2.0. Bioinformatics. 2007;23:2947-8.

28. Hall TA. BioEdit: a user-friendly biological sequence alignment editor and analysis program for Windows 95/98/NT. Nucleic Acids Symp Ser. 1999;41:95-8.

29. Martin DP, Williamson C, Posada D. RDP2: recombination detection and analysis from sequence alignments. Bioinformatics. 2005;21:260-2.

30. Lober C, Anheier B, Lindow S, Klenk HD, Feldmann H. The Hantaan virus glycoprotein precursor is cleaved at the conserved pentapeptide WAASA. Virology. 2001;289:224-9.

31. Kukkonen SK, Vaheri A, Plyusnin A. L protein, the RNA-dependent RNA polymerase of hantaviruses. Arch Virol. 2005;150:533-56.

32. Yadav PD, Vincent MJ, Nichol ST. Thottapalayam virus is genetically distant to the rodent-borne hantaviruses, consistent with its isolation from the Asian house shrew (Suncus murinus). Virol J. 2007;4:80.

33. Klempa B, Witkowski PT, Popugaeva E, Auste B, Koivogui L, et al. Sangassou virus, the first hantavirus isolate from Africa, displays genetic and functional properties distinct from those of other murinae-associated hantaviruses. J Virol. 2012;86:3819-27

34. Nemirov K, Vapalahti O, Papa A, Plyusnina A, Lundkvist A, et al. Genetic characterization of new Dobrava hantavirus isolate from Greece. J Med Virol. 2003;69:408-16.

35. Maes P, Klempa B, Clement J, Matthijnssens J, Gajdusek DC, et al. A proposal for new criteria for the classification of hantaviruses, based on $\mathrm{S}$ and $\mathrm{M}$ segment protein sequences. Infect Genet Evol. 2009;9:813-20.

36. Heyman P, Vaheri A, ENIVD Members. Situation of hantavirus infections and haemorrhagic fever with renal syndrome in European countries as of
December 2006. Euro Surveill. 2008;13. http://www.eurosurveillance.org/ ViewArticle.aspx?Articleld=18925

37. Heyman P, Vaheri A, Lundkvist A, Avsic-Zupanc T. Hantavirus infections in Europe: from virus carriers to a major public-health problem. Expert Rev Anti Infect Ther. 2009;7:205-17.

38. Plyusnin A, Morzunov SP. Virus evolution and genetic diversity of hantaviruses and their rodent hosts. Curr Top Microbiol Immunol. 2001;256:47-75.

39. Easterbrook JD, Klein SL. Immunological mechanisms mediating hantavirus persistence in rodent reservoirs. PLoS Pathog. 2008;4:e1000172.

\section{Submit your next manuscript to BioMed Central and we will help you at every step:}

- We accept pre-submission inquiries

- Our selector tool helps you to find the most relevant journal

- We provide round the clock customer support

- Convenient online submission

- Thorough peer review

- Inclusion in PubMed and all major indexing services

- Maximum visibility for your research

Submit your manuscript at www.biomedcentral.com/submit
) Biomed Central 